\title{
Judicial perspectives on the sentencing of minor drug offenders in Indonesia: discretionary practice and compassionate approaches
}

\author{
Cecep Mustafa ${ }^{1}$ (D) $\cdot$ Margaret Malloch $^{1}$ (1) $\cdot$ Niall Hamilton Smith ${ }^{1}$
}

Published online: 12 May 2020

(C) The Author(s) 2020

\begin{abstract}
This paper explores the perceptions of Indonesian Judges in sentencing minor drug offenders. The Judge holds a central role in the administration of justice and, because of the significance of judicial discretion, it is essential to understand how judges come to their sentencing decisions. To develop an understanding of what judges are trying to achieve when sentencing minor drug offenders, a total of 31 judges were interviewed: 28 participants came from District Courts in Urban and Rural jurisdictions in Indonesia (17 from Urban Courts and 11 from Rural Courts) and three were Supreme Court judges. The findings highlight that the process of justice involves not merely the application of the rule of the law or relevant legal codes; rather, how the judiciary balance and interpret the law is a central part of court sentencing practice.
\end{abstract}

\section{Introduction}

The context of sentencing is a crucial area to complement existing literature on the sentencing of individuals prosecuted for minor drug ${ }^{1}$ offences $[35,36]$. An important part of the context consists of the legal culture in which sentencing practices operate $[12,13,22]$. Court processes and practices have an influence on how discretionary power is understood and applied. The aim of this paper is to explore the forms of justice which operate within the context of the Indonesian legal culture as applied to sentencing practice in relation to minor drug offences.

\footnotetext{
${ }^{1}$ In this paper, unless stated otherwise, I use the term 'illegal drugs' to describe drugs, controlled under the 2009 Indonesian Drug Act, such as cannabis and methamphetamine.
}

Cecep Mustafa

cecep.mustafa@stir.ac.uk

Margaret Malloch

m.s.malloch@stir.ac.uk

Niall Hamilton Smith

niall.hamilton-smith@stir.ac.uk

Extended author information available on the last page of the article 
In the history of Western jurisprudence, there are three traditional forms of justice according to Duff [9]: legal, moral, and social. The first traditional form of justice is legal justice where judgments are made in compliance with the law. Legal justice operates within different legal cultures, of which there are at least two, one being common law, and the other, written law [30]. In written law cultures, such as in Indonesia, the judiciary does not create legal precedents but it is nevertheless involved in the interpretation of written legal rules. As will be presented in this paper, the judiciary can be considered bound by the principle of legality, which may constrain discretionary practices. For example, drug offences are listed in a penal code which requires the judiciary to follow and apply the codified rules. In contrast, common law provides more opportunity for judges to craft their sentences, but as a result, the judiciary may need to follow sentencing guidelines to avoid disparity. This acknowledges the way, within common law culture, that the application of the rule of law is implemented through sentencing practices [11]. However, even in Indonesia where judges must follow a written penal code, variations in sentencing still occur due to cultural differences that inform judicial consideration of the application of the rule of law when sentencing drug offenders.

A number of other factors can also influence the enforcement of the law in Indonesia where police and prosecutors are governed by the Executive (Chief Minister and Attorney General appointed by the President). This can affect the independence of law enforcement in the process of justice. The way in which the police define and prosecute individual cases, and the way evidence is then presented by the prosecutor may, in turn, influence judicial independence in the interpretation of facts and their relevant legal application. Thus, such structural factors (i.e. the extent of social circumstances that enter into Judges' deliberations) when sentencing individuals convicted of minor drug offences is worthy of exploration. The aim of this paper is therefore to explore both the cultural and structural influences on Indonesian judicial decision making. This paper is based on primary research into the perceptions of Indonesian judges in relation to sentencing practice relating to minor drug offences.

\section{Method}

To develop an understanding of how judges make decisions when sentencing individuals charged with minor drug offences, a total of 31 judges were interviewed: 28 participants came from the District Courts in Urban and Rural jurisdictions in Indonesia (17 in Urban Courts and 11 in Rural Courts) and three were Supreme Court judges.

The qualitative research was carried out in two district courts, termed 'the urban court' and 'the rural court' based on their geographic settings. These Courts, located on two different Indonesian islands, were based in localities that were markedly different in terms of socio-economic conditions. These differences in turn impacted on available resources for criminal justice, with disparities in the availability of and access to treatment for those convicted of drug offences. These differences also characterised the social context and, ultimately, the judiciary's contextualised perspectives on sentencing practices in relation to minor drug offences.

Concerning the selection of participants, the participants in Urban and Rural courts were purposively chosen in a way most likely to shed light on the research question. 
The context of the participants who worked in Urban and Rural courts and their various characteristics such as experience and training, was anticipated to potentially affect judicial perspectives on sentencing. All judges, within the Urban and Rural Courts that formed the basis for this study were included to obtain a range of perspectives. Of the 31 participants interviewed, some had been relocated to another jurisdiction by the time of the research but were still willing to participate.

For this study, court hearings were observed every 2 weeks in each participating court $(n=8)$, and included observation of sentencing practice for drug offences. A basic observation checklist was used to note judges' interactions with the accused/convicted during court hearings. This included interactions such as dialogue between judges and individuals being sentenced. Ethical approval for the study was obtained from the University of Stirling Ethics Committee.

\section{Theory}

It is noteworthy that during the last two decades there has been a growing body of literature exploring the relationship between sentencing and the structural circumstances that feature in the lives of those being sentenced. Nevertheless, many of these studies are located in Western jurisdictions and explore the relationship between sentencing practice and imprisonment $[5,23,36]$. The structural factors referred to in this paper, consist of the social forces that enter into Judges' deliberations, particularly the extent to which society labels drug use as deserving of punishment and where individuals who use drugs are therefore viewed as 'outsiders' [1]. This societal label is reflected in drug laws that prohibits drug use and lead to the imprisonment of drug offenders. It is likely that such labels can be perceived as factors that influence sentencing decisions [8]. Many studies indicate that societal labels and the demonisation of drug use among minorities in English-speaking countries appear to be attributable to the imprisonment of those belonging to the poorer classes and ethnic minorities. For example, Garland [10] notes that in the USA, the mass imprisonment of people of colour and immigrants imprisoned for drug offences can be interpreted as an attempt to segregate members of marginalized groups from members of the middleclass population. This is reflected in the imprisonment of those from marginalized groups for more prolonged periods, while middle-class citizens remain hidden from the criminal justice system. A wide range of other scholars have also made links between mass imprisonment in the USA, ${ }^{2}$ active class discrimination, and the criminalization of black and lower class drug offenders (e.g. [2, 3, 15, 19, 23, 29]. For example, in US jurisdictions, individuals who could not afford to pay for voluntary drug treatment programmes were more likely to be perceived by judges as being less suitable for rehabilitation [33]. Similarly, in European studies, the consumption of drugs was likely to result in disproportionate punishment [14]. However, it is noteworthy that most available studies are based on Western jurisdictions with very limited research exploring the interplay between social structural issues when sentencing minor drug offences in developing countries [36] and notably less in Indonesia (although note [20]).

\footnotetext{
${ }^{2}$ For example the mass imprisonment for minor drug offences $[28,31]$ and disparities in drug sentencing in the USA [7, 27, 32].
} 
Indonesian sentencing practice and its theoretical context has historically developed along retributive lines. In a retributive approach, the aim of sentencing is to communicate that no one profits from breaking the law [21, 34]. Therefore, Judges whose practice is informed by retributive aims are likely to impose punishment based on their perception of the seriousness of the drug offence. The focus on retributive measures for drug offences has led to the punishment model of sentencing. Studies have shown that if strong retributive measures are carried out, developing countries in Asia, including Indonesia, are likely to encounter the reproduction of socio-economic problems through the increasing use of imprisonment [24, 25]. More recently, studies of sentencing practices for drug-related offences have noted an evolution from retributive to rehabilitative approaches. Judges who have rehabilitative orientations may be more likely to encourage re-engagement with society and its' social and legal values $[8,9]$.

In the development of legal regulations in Indonesia there has been a paradigm shift. Drug users, who were once considered as "perpetrators of crime" and who were subject to punishment accordingly, are now often seen as "victims" deemed worthy of rehabilitation. The legal regulation 01/2014 (SKB) introduced treatment provisions ruling that: "(1) those convicted, who become drug addicts and victims of abuse of drugs are eligible to medical rehabilitation and/or social rehabilitation". This paradigm shift has not always been fully understood, or supported, by law enforcement agencies who have made limited use of rehabilitative measures.

A number of influencing factors can be identified in the development of legal regulations.. In 2001, Chambliss and Seidman noted that power relations feature in every stage in the implementation of legislation [6]. These recent changes in regulations and sentencing options, whilst being introduced to support social reform, need to be underpinned by a supportive legal culture if they are to be effective. The work of Chambliss and Seidman [6], with their emphasis on how power relations feature in the formulation and implementation of legislation, is important here. The basis of the law is not merely in written words and legal principles, but in the community context in which laws are enacted [6].

\section{The Indonesian context}

The link between the socio-economic context and the significance of drug use in Indonesia is important. Use of drugs is notable among specific social groups, for example for example, the use of amphetamine to increase the stamina needed by labourers for undertaking hard manual labour. This link has been exacerbated by more recent socio-economic developments and reforms which have increased inequality and in particular the gap between manual and skilled labour in terms of pay and conditions. Understanding these socio-economic conditions is essential for understanding the differential use of drugs between different social groups in Indonesia. Nasir et al. [25] have indicated that the majority of those prosecuted for drug offences in Indonesia live in urban neighbourhoods, although more generally, it is a practice that features across both rural and urban neighbourhoods. The high-level of underemployment among young people is also suggested as a feature of drug use and criminalisation [24]. It would certainly appear that the the majority of those brought to court for minor drug offences come from more impoverished backgrounds. This may be related to 
patterns of drug use or, as suggested above, processes of criminalization and law enforcement practices (for example systemic biases in investigations, prosecution, court hearings, and judicial interpretations of presented 'facts').

Nicholson [26] indicates that the influence of policing practices on judicial interpretation can be considered challenging. For example, in the post-2009 $\mathrm{era}^{3}$ following an Indonesian period of enforcement that was characterized as a 'war on drugs', Judge Mulyadi was concerned about policing practices in Indonesia [20]. Drug users who were undergoing rehabilitation could still be charged for criminal offences based on their past drug history and subsequently be prosecuted. Mulyadi's concern was that individuals who had completed residential rehabilitation might be targeted by the police after their treatment had ended and could be arrested at that point.

In terms of prosecution, the influence of the prosecutors when presenting evidence is also important in judicial decision-making. The presentation of evidence within the Indonesian criminal justice system, is similar to wider adversarial systems [17]. Prosecutors are required to present evidence. This presentation of evidence is initiated by establishing the identity of the defendant and presenting the indictment. Once the defendant understands the aim of the indictment, the witnesses (i.e. the police) are asked to testify. To assess levels of drug use, an assessment is obtained from a psychiatrist and urine testing results obtained. If necessary, psychiatric testimony is requested [16]. A panel of Judges then examines the evidence presented to the court. The defendant is subsequently presented to the court after which the panel of three Judges analyse and discuss the evidence in a confidential meeting. Consultation is based on the facts that have been proven and the indictment. The following discussion presents the findings of the study and highlights the operation and enactment of judicial discretion throughout this process.

\section{Findings}

\section{Inequality in sentencing}

This section presents the participants' perceptions that certain social groups within Indonesian society were more likely to use drugs and to be prosecuted for doing so. Interviews with judges across the two participating courts revealed that after the 2009 Indonesian Drug Act, people from lower socio-economic groups and those experiencing poverty were more likely to be targeted by the criminal justice system. Consequently, most of the people charged with breaking this new Drug Law were from underprivileged/poorer backgrounds. Some of the research participants noted that in their view, these people did not receive appropriate treatments (e.g. rehabilitation) and were therefore at disproportionate risk of being imprisoned. For example, Judge 5 (Urban) described how during the pre-Reformation eradrug use was a 'trend', a feature

\footnotetext{
3 The term "Reformation" refers to the end of New Order Era during the Suharto regime. The New Order Era was focused on economic development and was less focused on developing democratic systems. The Drug Law 35/2009 was introduced after the Reformation era. After the Reformation era, the provisions of drug sentencing were set under standard minimum sentencing. The provision required the judge to adhere to the standard minimum length of imprisonment required by the law. This impacted on judicial discretion limiting them from delivering a sentence below the standard minimum sentencing.
} 
of fashionable urban leisure. By contrast, during the Reformation era, drug consumption was made a crime, and those from underprivileged/poorer backgrounds were at risk of being arrested. The following excerpt indicates this point:

In 2008, when the former drug law was in use, [there were larger numbers of drug use, however, there was a lower number of people sentenced] [...]. At that time narcotics was considered a "trend'. For example, the elite classes hanging out on the street in an affluent area would often take ecstasy on a Sunday evening. The people who resided in poorer areas deemed this the lifestyle and drug consumption of choice of the elite classes. Nowadays, drug consumption is seen as a crime and the average person accused/charged with drug consumption is from an underprivileged/poorer background. (Judge 5, Urban)

The above quote indicates that Judge 5 is aware that drug users from underprivileged/ poorer backgrounds are more likely to be arrested. A substantial minority of the participants (i.e. 5 of the 31 ) frequently explained that the majority of people charged with breaking the new drug laws were from lower social backgrounds. This can be seen as an indication of the discriminatory effects that the war on drugs has on people from less affluent backgrounds. Furthermore, a substantial minority of the participating judges in the Rural Court stated that the criminal justice system often targeted lowerclass drug users. For example, Judge 28 (Rural) described how the views of those convicted. The judge noted:

I ask the offenders: "why do you use methamphetamine?" $90 \%$ of them coming from a lower class replied: "the first is to increase my stamina for undertaking hard manual labour"; this is the dominant perception among drug offenders. $10 \%$ of them, who come from the middle class, replied that "drugs are perceived as a way of life." (Judge 28, Rural)

Along a similar line, Judge 8 (Urban) stated: "So far, as I have observed during the court, the offender I sentence is not a middle-class person, actually, they are rarely from the middle class" (Judge 8, Urban). Judge 12 (Urban) also commented,

At the moment, those who are being arrested are mostly low-level offenders, while the drug dealers remain hidden, and the police will close the cases. By contrast, those who use one smoke, or those who are found using drugs, although the quantity of drugs is only zero points zero, their cases will be brought to the court. (Judge 12, Urban)

A minority of the participants (i.e. 4 from 31 ) suggested reasons why people from poorer backgrounds may use drugs to a greater extent than people from more affluent backgrounds. Judge 6, for example, indicated: "The motive is economic problems, obviously, the offenders have no jobs, and unemployment weighs heavily, and citizens are marginalized because of their behaviours...." (Judge 6, Urban) In urban areas, unemployment becomes an issue; this is the reason why people want to sell drugs because they receive not only commission for selling drugs but, also, receive free drugs to use. So, they have a dual role, for example, the price of drugs is Rp50,000.00 (around £3.00), the person will receive a 
commission from both the seller and the buyer and will be allowed to have a sample of drugs for his own use. (Judge 14, Urban)

A substantial minority of the Rural Court participants (i.e. 3 from 11) claimed that drug taking often occurred because of the environment. As Judge 20 (Rural) mentioned, "People use drugs just to have fun, or due to their unstable job status, or through curiosity about drugs, and peer influence..." (Judge 20, Rural). Similarly, Judge 23 (Rural) believed, "minor offenders are a perpetrator who, at the same time, becomes a victim of their circumstances. Sometimes, they become the victim of their circumstances due to peer influence and living in a drug dealing environment”. Participants noted three different reasons why lower-class citizens may be more likely to be convicted:first, poorer citizens may be more likely than wealthier citizens to get involved in drug culture, as can be seen in the following statement from a participating rural judge:

There is person $B$ who was persuaded initially to use drugs and, then, was forced to distribute them. When he had no capital to buy drugs and was living in a drugs culture and needing money for survival, then, he might carry out dual activities of both selling as well as using drugs for a commission. (Judge 19, Rural)

For Judge 19 (Rural), the offender's social circumstances were likely to be a motivation that influenced involvement in the drug economy. As stated by Judge 8 (Urban), "...once the person has an issue of drug use, he/she could do collective purchasing, 4 or alternatively, other ways such as stealing. This is the reason why despite his job is only a driver, he/she can purchase methamphetamine” (Judge 8, Urban). Similarly, Judge 27 (Rural) indicated, "Drugs seem to have become the disease; sometimes they are not aware of the effects and they continue to use them. These circumstances make me sympathetic, due to their doing everything to get drugs. They will sell everything available and this escalates to stealing”. According to Judge 27's assertion, drug use could increase the risk of being arrested due to involvement in other drug-related offences, often in order to obtain drugs. Seen in this way, both participating Rural and Urban Court judges described how poverty, drug culture, and living under drug prohibition regimes could be considered as contributing factors to more socioeconomically disadvantaged people becoming targeted by the police.

Second, it was noted by some participants (3 of 17), that discriminatory sentencing practices could be said to operate as the majority of the people charged with breaking the post-2009 Drug Law had limited funds and as a result, had no other choice than to accept imprisonment. The following statement from an Urban Court judge indicates this point:

The current problem relates to the requirement for doing rehabilitation... On the one hand, all the requirements for rehabilitation should be met. On the other hand, the offender should pay for the assessment. For those who become the victim of their circumstances and economically poor as beggars, they should receive rehabilitation. However, due to the challenges to meet the requirement for

\footnotetext{
${ }^{4}$ Personally, they have not enough money to buy drugs, so each person was contributing to buy drugs.
} 
receiving rehabilitation, there is no other choice for those poorer offenders than having to accept imprisonment. However, for those wealthy offenders, they receive rehabilitation no matter how large the quantity of drug evidence. (Judge 1, Urban)

As shown above, Judge 1 (Urban) asserts that the requirement for the accused to pay for an assessment could prevent poorer people from receiving rehabilitation. For Judge 1 , being poor could prevent equal access to treatment, resulting instead in a prison sentence. All participants expressed some degree of agreement that drug users were subject to discriminatory sentencing practices and a lack of opportunity to receive treatment.

\section{A moral basis for sentencing}

The desire to deliver a form of 'justice' to minor drug offenders appears to influence at least some of the participating judges in this study to make judgments on what they perceived to be a 'moral' basis. Recognition of discriminatory targeting and prosecution of drug users from poorer backgrounds influenced some participants (i.e. 5 from 31) to make compensatory judgements on a 'moral' basis, in so much that they attempted to demonstrate compassion and a lenient approach to sentencing. They conveyed that one should uphold one's moral responsibility both at the deliberation on sentencing and at the court hearings. Consider, for example, Judge 19's comment: "I think drug users have become victims of criminalisation" (Judge 19, Rural). For Judge 23 , this lenient response was a deliberate strategy to minimise the negative impact on those being sentenced. Judge 23 stated, "Because they [the offenders] were victims of circumstances- right? Essentially, they are not harming others but harming themselves" (Judge 23, Rural). For other participants, the moral responsibility of sentencing was a factor that should be taken into account at court hearings. At the court hearings, Judge 19's (Rural) panel tried to facilitate the offender receiving a lawyer's services for mitigation aims and in an attempt to minimize the negative impact of sentencing:

"Judge 19 Panel: You can make your mitigation, or your lawyer will do it for you. For the latter, we will give the lawyer one week to draft a plea of mitigation" (Extract from court hearing Observation Notes, Judge 19 Panel).

For other participating Rural Court judges, considering drug users as victims of their circumstances functioned as a way of minimising the negative impact of sentencing:

Those drug users are regarded as minor drug offenders because they are the victims of drug traffickers... I consider, also, the amount of evidence of daily drug usage and the offender's background; it is about why they became a victim of their circumstances. I saw that most became victims as a result of lack of parental supervision. (Judge 18, Rural)

A minor offender is a perpetrator who, at the same time, becomes a victim of their circumstances. Sometimes, he/she becomes the victim of circumstances due to peer influence and lives in a drug-dealing environment... This means that, initially, they are blindly following their peers. (Judge 26, Rural) 
The issue of social exclusion was raised by some judges from Urban Court (i.e. 2 from 17) who suggested that the issue of social exclusion should be considered at the judicial deliberation on sentencing. Judge 6 , for example noted that offenders who use drugs do not necessarily have drug 'problems', nor are they necessarily harmful to others or public order. As Judge 6 stated:

I would argue that those drug misusers are people who are not necessarily having issues of drug use... It was because of his/her friendship that he/she became either victim of drug trafficking itself or coerced or deceived or being cheated and so on, or being trapped... If the persons were using the drug for themselves, they were not doing evil and were not harming anyone. They were self-harming. I never agreed with the opinion that persons who use drugs were harmful to others or public order. No, it is not the case. (Judge 6, Urban)

\section{Sentencing based on compassion and moral responsibility}

The way in which compassion featured in sentencing practice appeared to differ across judges and courts. The following statements from the participating Rural Court judges illustrate this kind of deliberation on sentencing:

In my opinion, the judge is not the mouthpiece of the law since she/he could interpret the law differently. Therefore, we feel that the law aims to improve conditions, to organise life and to manage everything in order. (Judge 23, Rural)

Judge 23 expressed a view that that judges can sentence in ways that could act to improve the offender's conditions. This discretion could be applied to minimise the stigmatising effects of the criminal justice system. As a result of this, some participants in the Rural Courts (i.e. 3 from 11) noted that they attempted to pass lighter sentences to reduce the length of imprisonment, where a custodial sentence was imposed. Judge 25 (Rural) stated "... after release from the detention centre, the offender again is willing to receive rehabilitation". In Urban Courts, three judges commented on the importance of developing self-awareness and reflexivity in sentencing: "I hope that the judge will be wiser in holding the court hearing and not strictly follow the rules" (Judge 12, Urban). "I invited the panel to consider it with honesty and reflexively, as we imagine that we are in the position of the offender.. I encouraged panel judges to consider from their hearts" (Judge 9, Urban).

\section{Stages of sentencing}

A number of variations were evident in sentencing stages between the different Courts. As an example, Judge 31 (Supreme Court) suggested the importance of interpreting the facts and the relevant law. Judge 31 also tried to respect colleague judges' perspectives in this process: 
There are two perspectives on sentencing minor drug offenders. The first perspective which we consider is that, although the offenders are arrested for possession of drugs, the offenders are sentenced under Rule 111 committing drug possession... The second perspective which we consider is that, although the offenders are just finished using drugs, then the offenders were carrying the remaining drugs, and then the remaining drugs were found by the police. In my opinion, the judges should not follow the Rule $111^{5}$ because the offenders are drug misusers. ${ }^{6}$ (Judge 31, Supreme Court)

This did not mean that judicial interpretation of the facts and the relevant laws related solely to the quantity of drugs involved, but that they also took account of previous drug use, and positive or negative urine tests as evidence of daily drug usage. As the following extract indicates:

In my opinion, a person who takes a drug would test positive for methamphetamine. It would then be misleading to assume the person was possessing drugs with intent to sell even though they tested positive. Positive drug testing does not tell us how the offenders sold the drug, when the offenders sold the drug, or to whom the offenders sold the drug. A positive drug test would give insight that the person has used drugs [...] If the quantity of drugs is smaller [...] [the participant then asked me to] see the Supreme Court circular ${ }^{7}$ also, number 3 from the year 2011. (Judge 31, Supreme Court)

The above excerpts highlight the Supreme Court judge's adoption of an individualised approach to find a better way of interpreting the facts and the relevant law. However, the adoption of an individualised approach was not fully reflected in the approaches taken by judges in the Lower Courts. Judge 4 (Urban) demonstrated their approach to sentencing for small quantities of daily drug usage:

One day, in 2013, I proceeded with a drugs case, the quantity of evidence of daily drug usage was very light, it was less than two grams, and the offender was a foreigner. It was then that I imposed minimum sentencing by the quantity of evidence of daily drug usage. (Judge 4, Urban)

The above excerpts (i.e. Judge 31 and Judge 4) indicate that the Urban Court judge's approach to impose minimum sentencing was, in some cases, contrary to the Supreme Court's expectation. For smaller quantities of drugs, the 2010 Supreme Court Circular number 4 and 2011 Circular number 3 regarding rehabilitation should have been

\footnotetext{
${ }^{5}$ Rule 111 is concerned with the illegal possession of drugs in the form of a plant (e.g. cannabis). This rule holds a standard minimum-maximum tariff of 4 to 12 years. Rule 112 is concerned with the rules about illegal possession of synthetic drugs (e.g. methamphetamine). This rule holds a standard minimum 4 years and a maximum of 12 years.

${ }^{6}$ Rule 127 is concerned with the rule about drug misuse. Rule 127 enables a choice to be made between drug misuse either being punished by imprisonment or sent for treatment.

${ }^{7}$ Both SEMA 2010 and SEMA 2011 set the maximum quantity of drugs being used at the time of the offender being arrested, which is eligible for rehabilitation. According to both SEMA 2010 and SEMA 2011, the maximum quantity of evidence of drugs being used is $1 \mathrm{~g}$ of methamphetamine, and $5 \mathrm{~g}$ of cannabis.
} 
applied. However, the findings indicate some variations in practice with the adoption of an individualised approach. The interviews indicated that for some judges, evidence of daily drug use was considered, but at the same time, judges were able to consider the reasons behind the individual's drug use. The following extract illustrates this point:

I consider, also, the quantity of the evidence of daily drug usage. Whether it is a large or a small amount. Whether they use drugs regularly; whether at the time of being arrested the urine is positive or negative; the reason behind his drug use; whether he has been sentenced previously; and whether he is purely a drug user or whether he has a dual role as the trafficker or doing business with drugs. (Judge 23, Rural)

Similarly, Judge 6, noted:

I shall see how the accused relates the story of the violation of law or criminal acts, for example, whether he was a dealer, whether he sells, whether his motive was economic, profits, or no reason or, more importantly, the negative impact to the young Indonesian generation. (Judge 6, Urban)

Judge 9 (Urban) also adopted an individualised approach in their interpretation of the facts during Court hearings in order to give some consideration to the offender's circumstances and whether they were, as perceived by the judge, as 'genuine':

If we look in depth at the consistency of the information about the offender, ranging from the investigation to the court hearing, there is always one consistent theme. No matter whether the type of question is rephrased and twisted, the answer will remain the same; on that condition, it is likely that that the offender is truthful. (Judge 9, Urban)

Judge 30 (Supreme Court) further expected judges to consider wider circumstances that went beyond the prosecutorial indictment:

It was found after the court hearing that the offender was convicted as a drug user; however, the Rule 127 on drug use was not part of the indictment. Therefore, recently, we agreed that the convicted offenders would be sentenced under Rule 127 as a drug user... If the urine is positive and a bit of cannabis is found, then we believe that this man bought cannabis or methamphetamine as such for consumption only. (Judge 30, Supreme Court)

The participating Supreme Court Judges considered that, although Rule 127 on drug users was not part of the indictment, as long as the offender was convicted as a drug user the convicted offender would be sentenced as a drug user rather than as a dealer or supplier, and could be sentenced accordingly. 


\section{Assessment of sentencing}

A number of participating Rural Court judges explained that they perceived the importance of understanding human factors in their decision-making. For example, as stated by Judge 20 below:

People use drugs just for having fun, or due to their unstable job status, or through curiosity about drugs, and peer influence. Women use drugs during pregnancy even though they will be giving birth. These are all human factors. (Judge 20, Rural)

The circumstances of women convicted of drug offences and who were perceived as having multiple responsibilities within the home were often taken to be mitigating factors in sentencing decisions. Some judges expressed sympathy for women's circumstances and, as a result, led them to sentence women leniently. As Judge 13 remarked: "...I do sentence the women more lightly than men due to women not only having responsibility for childcare but, also, to support the family income. Those factors made the sentencing of women lighter than for men" (Judge 13, Urban). Along a similar line, Judge 2 mentioned:

The sentencing of female offenders will be more lenient than sentencing of male offenders. Normally, the gender of the offender influences the judge's sentencing... Other mitigating speeches are such as "because my children need milk, and there is an opportunity to get easy money" these speeches make me sympathetic. (Judge 2, Urban)

Similar considerations were evident in decision-making in relation to children who were brought before the courts. For children ${ }^{8}$ and young people, decisions were subject to 'best interest' judgements and on this subject, judges indicated their interest in paying attention to the needs of children. Judge 18, for example, mentioned: "I tend to rehab or return those children who use drugs to their parents because none of their parents wanted their children to become victims of their circumstances" (Judge 18, Rural). In the same vein, Judge 17 stated, "For children who use drugs, if the evidence of daily drug usage shows a few drugs, this will lead us to believe that, once children who use drugs receive rehab and treatment and therapies, they will not do drugs anymore" (Judge 17, Urban). In a more detailed sense, Judge 8 believed that children should not be imprisoned, noting:

The sentencing of those children who use drugs is not imprisonment since we are trying to return those children to society and sent them back to their parents. We will consider the opinion of the correctional officer for children (BAPAS), the parents and we will consult with the psychologist to understand the underlying factor that puts the children in trouble. (Judge 8, Urban)

\footnotetext{
${ }^{8}$ The Juvenile Court Law indicates that child offenders are those aged between 8 to 18 years.
} 
The Supreme Court echoed the judicial interest in assessing children's best interests, as Judge 29 stated: "The judge is free to sentence in the interests of saving the children and means that the standard minimum sentencing is not applied to children" (Judge 29, Supreme Court). Accordingly, in the case of children, there was scope for background circumstances and the stigmatising effects of sentencing to be compassionately considered. Judge 14 notes:

...The meaning of possession should be clarified because it is unfair to apply the drug law without considering it from a variety of angles. For example, we consider if the case attracts public attention, the effect of sentencing, the background behind drug dealing and whether it is for doing business or due to a lack of income or over making an income. (Judge 14, Urban)

\section{Discussion}

It can be seen from the findings presented above that judges recognized the impact of social circumstances such as poverty, and the ways in which this often led people to become targets of the criminal justice system and to end up in prison. The socioeconomic issues were also perceived by research participants to limit the available choices that might otherwise prevent individuals from using drugs. Thus, minor drug offenders were often considered, by the judges in this study, to be on occasions, victims of their circumstances. Poverty and the use of drugs by some to increase their stamina for undertaking hard manual labour was noted by research participants. Based on these points, it can therefore, be argued that drug taking in Indonesia reflects the economic inequality in broader social structures. This is aligned with the argument made by [4, 5]) that socio-economic disadvantage is one experience which itself is often unjust. Within circumstances of structural inequality, the imposition of sanctions on minor drug offenders who experience socio-economic disadvantage can in itself, highlight problems surrounding the delivery of justice. This finding support Wexler [37] who advocates the importance of judges delivering a sentence that reflects the circumstances of individuals who already experience socio-economic problems.

This involved displaying sensibilities that involved the exercise of discretion, encouraging the participants to redefine sentencing options beyond imprisonment [9, 18]. These participants attempted to reduce the length of sentence with the aim of releasing minor drug offenders from prison earlier than required by the legislation and which could enable them to receive treatment outside prison. The perceived, moral responsibility of some participating judges, shaped the presentation of leniency evident in such practices as disregarding the standard minimum sentencing criteria.

There are some limitations in the study that are worth noting. The relatively small sample of panel judges who participated in the study, although comparable with other similar qualitative studies and justified by the contextualised of the data collected, limits the generalisability of the findings outside the Indonesian jurisdiction. Similarly, the study can only provide a partial picture of justice for minor drug offenders in the Indonesian context since it examined empirical evidence obtained from judges working 
in a particular province of Indonesia. It was not feasible to obtain the views of all judges in the jurisdiction (there are currently 3034 district court judges in Indonesia).

The study can only provide a partial picture of structural inequality from the judge's perspective. It can be seen from the findings that the majority of minor drug offenders brought into the court came from more impoverished backgrounds. Nevertheless, the available evidence across Indonesia does not suggest that this picture is different elsewhere in the country. In the context of Indonesia, socio-economically disadvantaged offenders have become disproportionately a target of the criminal justice system. They are punished because their social economic circumstances mean they are easily identifiable and subsequently, are easy to arrest. They are often vulnerable due to being unable to have their rights recognised or to have them upheld in Court. Within Indonesia, drug cases often become a source of income for criminal justice professionals and accordingly, those socio-economically disadvantaged offenders who are unable to give a bribe to the law enforcement officer are more likely to find that their cases are altered from drug use to drug possession; an offence which is subject to 4 years' imprisonment. Even when their case is presented as one of personal use rather than supply, they are unlikely to receive an assessment for rehabilitation and miss the opportunity to receive treatment. This is because often assessment and treatment is offered to those who can pay. This contrasts with middle-upper class offenders, who remain hidden from the criminal justice because, although they are arrested, are more likely to be released early and have their cases closed.

\section{Conclusion}

In this paper, the different perspectives and understandings that underpin the judicial response to sentencing practices in relation to minor drug offences have been presented. In particular, judicial perceptions of the significance of social position and the disproportionate presence of more marginalized citizens in the criminal justice system has been highlighted. For many participating judges, class structure had a direct influence on the context of sentencing in two different ways. First, it was acknowledged that the war on drugs has targeted less advantaged citizens and is therefore discriminatory. Most of the people charged with breaking the 2009 Drug Law were from poorer socioeconomic backgrounds. In contrast, middle-class drug users were not the target of its sanctions. Second, the people who were more likely to experience poverty failed to receive treatment, and it appears that for a number of participating judges this could be attributed to the inequality of access to treatment. Consequently, this affects how justice is conceptualized within the judicial system, leading a number of participants to make judgments on a moral basis; i.e. exercising compassion and moral responsibility in sentencing.

This compassionate approach to minor drug offenders in Indonesia leans toward individualised approaches to sentencing, through discretionary practice where this was possible. The finding of the interviews showed that the potential for discretionary practice could be either lenient or punitive, depending on personal attitudes toward drug use. Various factors were considered by participating judges, including the judicial interest in the case, 'risk assessment' and the impact of sentencing on the wider society. Participants stated that they were interested in paying attention to the needs of the 
offender's family and children. For example, children who used drugs could be returned to their parents rather than sentenced to imprisonment. Some participants gave examples of how they took the background to individuals drug offences, and the stigmatising effects of criminal justice interventions, into account in ways that showed a degree of compassion. Recognition of drug prohibition regimes and the contributing factors of drug users being targets of criminal justice sanctions were also acknowledged by some participants. The recent enforcement of a drug law which could contribute to the structural inequality of sentenced offenders caused concern to some participants. These considerations illustrated that judges do not expect to merely follow the discriminatory practices of the enforcement of a drug law which they may perceive as contravening the pursuit of justice in the judicial system. This is an important instance of judges within an apparently rigid written law system exercising a level of discretion that may be more typically attributed to decision making in common law systems.

Within the context of Indonesian courts, which are primarily retributive and against a backdrop of increasingly draconian drug prohibitionist policies, evidence of problemsolving and the adoption of compassionate approaches to justice in some of these courts is arguably a welcome corrective. This attempt by some of the judiciary, to focus on the moral basis of sentencing - as Indonesian judges perceived it - in a context of punitive legislative practice, makes this study significant and highly original in the field of judicial sentencing generally and in relation to minor drug offenders specifically.

Acknowledgments I thank the anonymous reviewers for their support in reviewing this paper. I thank the 31 participants who agreed to be interviewed, and the Indonesian Endowment Fund for Education (LPDP).

Authors contributions Writing - original draft: Cecep Mustafa.

Writing - review \& editing: Margaret Malloch, Niall Hamilton Smith.

Funding information This work was supported by the LPDP [grant numbers 5-259/LPDP, 2013].

Open Access This article is licensed under a Creative Commons Attribution 4.0 International License, which permits use, sharing, adaptation, distribution and reproduction in any medium or format, as long as you give appropriate credit to the original author(s) and the source, provide a link to the Creative Commons licence, and indicate if changes were made. The images or other third party material in this article are included in the article's Creative Commons licence, unless indicated otherwise in a credit line to the material. If material is not included in the article's Creative Commons licence and your intended use is not permitted by statutory regulation or exceeds the permitted use, you will need to obtain permission directly from the copyright holder. To view a copy of this licence, visit http://creativecommons.org/licenses/by/4.0/.

\section{References}

1. Becker, H. (2008). Outsiders: Studies in the sociology of deviance. New York: The Free Press of Glencoe. Retrieved from http://search.ebscohost.com.ezproxy-s1.stir.ac.uk/login.aspx?direct=true \&db= edsasp\&AN=edsasp.ASPS10020155.soth\&site=eds-live.

2. Buchanan, J. (2006). Understanding problematic drug use: A medical matter or a social issue. British Journal of Community Justice, 4(2), 387-397. Retrieved from http://search.ebscohost.com.ezproxy-s1. stir.ac.uk/login.aspx?direct=true $\& d b=$ sih $\& A N=21685499 \&$ site $=$ eds-live. 
3. Buchanan, J. (2015). Ending drug prohibition with a hangover? British Journal of Community Justice, 13(1), 55. Retrieved from http://search.ebscohost.com.ezproxy-s1.stir.ac.uk/login.aspx?direct=true \&db= sih\&AN=103147181\&site=eds-live.

4. Carlen, P. (1994). Crime, inequality, and sentencing. In D. Garland \& R. Duff (Eds.), A reader on punishment (pp. 306-332). Oxford: Oxford University Press. Retrieved from http://search.ebscohost. com.ezproxy-s1.stir.ac.uk/login.aspx?direct=true \&db=sih\&AN=SM122193\&site=eds-live.

5. Carlen, P. (2013). Against rehabilitation; for reparative justice. In Crime, justice and social democracy (pp. 89-104). London: Palgrave Macmillan. https://doi.org/10.1057/9781137008695_6.

6. Chambliss, W. J., \& Seidman, R. B. (2001). Law, order, and power (p. 3). Reading: Addison-Wesley.

7. Chen, E., \& Nomura, K. (2015). And justice for all? Racial and ethnic disparities in Federal Drug Courts in California and the US. California Journal of Politics and Policy, 7(2), 1. https://doi.org/10.5070/P2 CJPP7227275.

8. Duff, R. A. (2001). Punishment, communication, and community. Retrieved from https://ebookcentral. proquest.com.

9. Duff, R. A. (2011). Blame, moral standing and the legitimacy of the criminal trial. Ratio, 23(2), 123-140. https://doi.org/10.1111/j.1467-9329.2010.00456.x.

10. Garland, D. (2001). The culture of control: Crime and social order in contemporary society. Chicago: University of Chicago Press. https://doi.org/10.7208/chicago/9780226190174.001.0001.

11. Hart, H. L. A., \& Green, L. (2012). The concept of law. Oxford: Oxford University Press. https://doi. org/10.1093/he/9780199644704.001.0001.

12. Holmes, O. W. (2009). The common law. Cambridge: Harvard University Press. Retrieved from https://ebookcentral.proquest.com.

13. Hutton, N. (2006). Sentencing as a social practice. In S. Armstrong \& L. McAra (Eds.), Perspectives on punishment: The contours of control (pp. 155-174). Oxford: Oxford University Press. Retrieved from http://search.ebscohost.com.ezproxy-s1.stir.ac.uk/login.aspx?direct=true \&db=edsbl\&AN= CN062002851\&site=eds-live.

14. Kopenic, P. (2015). Interview of Kamil Ivanek, Slovakia, regional court of Bratislava. In D. Das \& R. Lowe (Eds.), Trends in the judiciary: Interviews with judges across the globe (Vol. 2, pp. 129-150). London: CRC Press. https://doi.org/10.1201/b17907-16.

15. Lassiter, M. D. (2015). Impossible criminals: The suburban imperatives of America's war on drugs'. Journal of American History, 102(1), 126-140. https://doi.org/10.1093/jahist/jav243.

16. Law 8/. (1981). (The Criminal Procedure of Indonesia).

17. Lindsey, T., \& Nicholson, P. (2016). Drugs law and legal practice in Southeast Asia: Indonesia, Singapore and Vietnam. Bloomsbury Publishing.

18. McIvor, G. (2009). Therapeutic jurisprudence and procedural justice in Scottish drug courts. Criminology and Criminal Justice, 9(1), 29-49. https://doi.org/10.1177/1748895808099179.

19. Melossi, D. (2008). Controlling crime, controlling society: Thinking about crime in Europe and America. Theoretical Criminology, 4, 513. Retrieved from http://search.ebscohost.com.ezproxy-s1.stir.ac.uk/login. aspx?direct=true $\& \mathrm{db}=$ edswst $\& A N=$ edswst. $1578918 \&$ site=eds-live.

20. Mulyadi. (2013). Punishment against traffickers and drug users: Research on principles, theory, and practice norms application in court (p. 147). Research Centre for the Indonesian Supreme Court.

21. Murphy, J. G. (2013). Retribution reconsidered: More essays in the philosophy of law (Vol. 54). Springer Science \& Business Media.

22. Myers, M. A., \& Talarico, S. M. (2012). The social contexts of criminal sentencing. Dordrecht: Springer Science and Business Media. Retrieved from https://doi-org.ezproxy-s1.stir.ac.uk/10.2307/800707.

23. Nadelmann, E. A. (2004). Criminologists and punitive drug prohibition: To serve or to challenge? Criminology \& Public Policy, 3(3), 441-450. https://doi.org/10.1111/j.1745-9133.2004.tb00052.x.

24. Nasir, S., Rosenthal, D., \& Moore, T. (2011). The social context of controlled drug use amongst young people in a slum area in Makassar, Indonesia. International Journal of Drug Policy, 22(6), 463-470. https://doi.org/10.1016/j.drugpo.2011.10.006.

25. Nasir, S., Rosenthal, D., \& Moore, T. (2014). "It's not easy but it's still possible to be an abstainer here": Non-drug use among young men in a slum area in Makassar, Indonesia. International Journal of Criminology and Sociology, 3, 336. https://doi.org/10.6000/1929-4409.2014.03.29.

26. Nicholson, P. (2017). The death penalty and its reduction in Asia: An overview. Asian Law Centre, Melbourne Law School, University of Melbourne.

27. Nunn, K. B. (2002). Race, crime and the pool of surplus criminality: Or why the war on drugs was a war on blacks. Gender Race and Justice, 6, 381. Retrieved from http://search.ebscohost.com.ezproxy-s1.stir. ac.uk/login.aspx?direct=true \&db=edshol\&AN=edshol.hein.journals.jgrj6.19\&site=eds-live. 
28. Pettit, B., \& Western, B. (2004). Mass imprisonment and the life course: Race and class inequality in US incarceration. American Sociological Review, 69(2), 151-169. https://doi.org/10.1177 /000312240406900201.

29. Provine, D. M. (2011). Race and inequality in the war on drugs. Annual Review of Law and Social Science, 7, 41-60. https://doi.org/10.1146/annurev-lawsocsci-102510-105445.

30. Reinmann, M., \& Zimmermann, R. (2008). The Oxford handbook of comparative law. Oxford: Oxford University Press. Retrieved from https://discoverlibrary-stir-ac-uk.ezproxy-s1.stir.ac. uk/iii/encore/record/C_Rb4342947.

31. Shiner, M. (2015). Drug policy reform and the reclassification of cannabis in England and Wales: A cautionary tale. International Journal of Drug Policy, 26(7), 696-704. https://doi.org/10.1016/j. drugpo.2015.03.009.

32. Spohn, C. (2015). Evolution of sentencing research. Criminology and Public Policy, 14(2), $225-232$. https://doi.org/10.1111/1745-9133.12125.

33. Ulmer, J. T., Kurlychek, M. C., \& Kramer, J. H. (2007). Prosecutorial discretion and the imposition of mandatory minimum sentences. Journal of Research in Crime and Delinquency, 44(4), 427-458. https://doi.org/10.1177/0022427807305853.

34. Von Hirsch, A. (2003). Punishment, penance, and the state. In D. Matravers \& J. E. Pike (Eds.), Debates in contemporary political philosophy: An anthology (p. 408). Abingdon: Routledge.

35. Ward, J. (2013). Punishing drug possession in the magistrates' courts: Time for a rethink. European Journal on Criminal Policy and Research, 19(4), 289-307. https://doi.org/10.1007/s10610-012-9191-1.

36. Ward, J. (2014) Are Problem-solving courts the Way Forward for Justice? Howard League What is Justice? Working papers 2/2014. Retrieved from https:/eprints.mdx.ac.uk/14571/.

37. Wexler, D. B. (2008). Rehabilitating lawyers: Principles of therapeutic jurisprudence for criminal law practice. Carolina Academic Press Retrieved from http://www.cap-press.com/books/1844.

Publisher's note Springer Nature remains neutral with regard to jurisdictional claims in published maps and institutional affiliations.

\section{Affiliations}

\section{Cecep Mustafa ${ }^{1} \cdot$ Margaret Malloch $^{1} \cdot$ Niall Hamilton Smith ${ }^{1}$}

Faculty of Social Science at the University of Stirling, Stirling FK94LA, UK 